\title{
EFFECTS OF INDUCTION-FURNACE SLAG ON STRENGTH PROPERTIES OF SELF-COMPACTING CONCRETE
}

\author{
Oluwaseun MARK ${ }^{1,{ }^{*}, \text { Anthony EDE }}{ }^{1}$, Chinwuba ARUM ${ }^{2}$, Solomon OYEBISI ${ }^{1}$ \\ ${ }^{1}$ Department of Civil Engineering, College of Engineering, Covenant University, PMB1023, km 10, \\ Idiroko Road, Sango, Ota, Ogun State, Nigeria. \\ ${ }^{2}$ Department of Civil Engineering, School of Engineering and Technology, Federal University of \\ Technology, PMB 704, Akure, Ondo State, Nigeria. \\ * corresponding author: oluwaseun.mark@covenantuniversity.edu.ng
}

\section{Abstract}

Indiscriminate waste disposal poses a severe environmental challenge globally. Recycling of industrial wastes for concrete production is currently the utmost effective way of managing wastes for a cleaner environment and sustainable products. This study investigates the strength characteristics of self-compacting concrete (SCC) containing induction furnace slag (IFS) as a supplementary cementitious material (SCM). The materials utilized include 42.5R Portland cement, induction furnace slag as an SCM ranging from 0 to $50 \%$ by cement weight at $10 \%$ interval, river sand, granite, water and superplasticizer. The fresh properties were tested for filling ability, passing ability and segregation resistance, the strength characteristics measured include compressive strength, splitting tensile strength, flexural strength and Schmidt/rebound number. The oxide compositions and microstructural analysis of SCC were investigated using $x$-ray fluorescence analyser (XRF) and scanning electron microscopy equipped with energy-dispersive $\mathrm{x}$-ray spectroscopy (SEM-EDS), respectively. Empirical correlations were statistically analyzed using MS-Excel tool. The filling ability characteristic was determined via both the slump flow test and the $\mathrm{T}_{50 \mathrm{~cm}}$ slump flow time test. Moreover, the passing ability characteristic was determined using L-Box test. The segregation resistance characteristic was determined using $\mathrm{V}$-funnel at $\mathrm{T}_{5 \text { minutes }}$ test. The results of the fresh properties showed a reduction in the slump flow with increasing IFS content. On the other hand, the $T_{50 \mathrm{~cm}}$ slump flow increased with increasing IFS content. Furthermore, the L-Box decreased with higher IFS content. On the contrary, the V-funnel at $T_{5 m i n u t e s}$ increased considerably with greater IFS content. The strength test results revealed that the strength properties increased to $20 \%$ IFS, with a value of $66.79 \mathrm{~N} / \mathrm{mm}^{2}$ compressive strength at 56 days, giving a rise of $12.61 \%$ over the control. The SCC microstructural examinations revealed the amorphous and better interface structures with increasing IFS content in the mix. The empirical correlations revealed that linear relationships exist among the measured responses (fresh and strength properties). Ultimately, IFS could be utilized as a sustainable material in producing self-compacting concrete.
\end{abstract}

\section{Keywords:}

Self-compacting concrete;

Concrete;

Strength;

Induction furnace slag;

Supplementary cementitious

materials.

\section{Introduction}

The most excellent construction material from human history is concrete [1, 2]. For this reason, it is doubtless that as modernization advances, concrete will be more relevant in construction industries. Notwithstanding, advancement in concrete production will continue to pose a serious environmental challenge [3]. Another way of advancing concrete production is by utilizing self- 
compacting concrete (SCC). Self-compacting concrete is concrete type which possesses the capability of filling all corners of formwork (good filling ability), passes through a congested reinforcement (good passing ability) and resists segregation under its weight [4]. Self-compacting concrete is relatively a new concrete type which is different from normally compacted concrete because it has high range water reducer, that helps to ease flow. SCC fills every corner of the formwork under its self-weight, with no form of vibration or compaction. SCC was firstly utilized in 1988, in Japan and was later adopted in 1990, in Europe, Sweden as well as Holland. SCC has been a very excellent alternative to normally-vibrated concrete in complex structures like curved as well as slender structures, where it is difficult in compacting normally-vibrated concrete, specifically where there are reinforcement congestions. Also, it is beneficial in the area of safety and health. Eliminating vibration results in eradication of vibration-related disease such as white finger disease, likewise making the site quieter [5].

Falmata et al. [6] worked on self-compacting concrete strength characteristics, including silica fume and fly ash at $0,25,40,50,60$, and $75 \%$ partial replacement by Portland cement. It was found out that the fresh properties (filling ability, passing ability as well as resistance to segregation) satisfied EFNARC guidelines for an SCC. From their study, 28 days' compressive strength gave the highest value of $79.73 \mathrm{MPa}$, which was obtained by combining $25 \%$ of Portland cement, $10 \%$ silica fume, $65 \%$ fly ash and cement content $146.88 \mathrm{~kg} / \mathrm{m}^{3}$. Twenty-eight days split tensile strength gave the highest value of $5.86 \mathrm{MPa}$. Likewise, the 28 days' elastic modulus yielded the highest value 86,676 $\mathrm{MPa}$. Thus, it was concluded that including fly ash and silica fume in producing self-compacting concrete reduced cement quantity and increased strength characteristics. Askari et al. [7] researched the strength characteristics of self-compacting concrete, including silica fume and blast furnace slag. It was discovered that the fresh properties satisfied the EFNARC guidelines, the compressive strength was also significantly improved from 28 to 120 days crushing age, indicating the increased pozzolanic property of blast furnace slag powder with time. Also, as the slag content increased, the split tensile strength reduced, but the split tensile strength improved upon the addition of silica fume up to $10 \%$. Ahmed and Ridha [8] observed the effect of steel fibre on lightweight aggregate concrete. The inclusion of steel fibre more than $2 \%$ may reduce the volume fraction, which is very significant in splitting tensile strength and slightly significant in density. Similarly, they discovered that as the steel fibre content increased, the crushing strength value increased. The crushing and splitting tensile strength values reduced more for the mix with normal weight sand and porcelinite coarse aggregate than those for the mix with natural river gravel and porcelinite fine aggregate. Therefore, the decrease depends on the mix, which includes normal weight sand and natural river sand. Snehal et al. [9] found that all self-compacting concrete mixes satisfy the criteria (slump flow ranges between $650 \mathrm{~mm}$ to $800 \mathrm{~mm}$ ) except for $60 \%$ fly ash replacement. Similarly, L-box test result showed that an increase in the percentage of fly ash reduces passing ability. Annie et al. [10] discovered that pile foundations constructed with SCC are more dimensionally stable and uniform than those built with typically vibrated concrete (NVC). The compressive and tensile strengths of the piles for both SCC and NVC were very close. Thus, the SCC pile is an excellent choice.

Slags are generally compositions of metallic and non-metallic oxides reacting with minute minerals, metallic sulphides, and gases. Foundry workers usually dump these slags on the foundry site, contaminating the land and reducing the soil fertility. Induction furnace slag contains close to $15 \%$ metals, of which many industries choose to disregard this valuable metal. Induction furnace slag is a waste product of cast iron generated in an induction furnace operated by electromagnetic induction principle, made use of in foundries [11]. Induction furnace slag is a basic slag that is different from blast furnace slag which is an acidic slag. Therefore, IFS is non-toxic, non-poisonous and noncorrosive, compared to the acidic BFS. Furthermore, for the fact that IFS is not corrosive, it improves the corrosion resistance of the resulting concrete, thereby improving the durability of such concrete, compared to a BFS-based concrete. IFS is also different from BFS in the sense that IFS is obtained from an induction furnace (a recent and modern form of producing iron and generating slag) while BFS is obtained from a combustion furnace (an old and crude form of producing iron and generating slag) [12]. In addition, IFS is a slag waste generated from cast iron production while BFS is a slag waste produced from pig iron production. From these aforementioned points, IFS has characteristics and compositions (both physical and chemical) different from BFS. Many researchers have investigated the potentials of utilizing BFS in making SCC but a few have investigated the potentials of using this new slag IFS in making SCC. However, induction furnace slag powder is obtained by pulverizing, milling, and sieving induction furnace slag to cement size. Using a cheaper SCM like induction furnace slag will reduce the total cost of producing SCC. The utilization of low-cost IFS also reduces the 
environmental stress generated through waste disposal. Likewise, IFS usage minimizes the need for cement in the construction industry and as a result, lowers the cost of production of concrete and reduces the pollution of the environment evolving from cement manufacturing industries. Therefore, IFS does not just improve concrete strength but also offers environmental and economic benefits.

John and John [13] investigated the utilization of IFS as fine aggregate in normal concrete. The compressive strength of concrete and the mortar increased up to $30 \%$ replacement of IFS with sand more than the control. Syed and Shafiqur [14] studied the strength and durability properties of concrete containing IFS and recycled aggregates (RA) obtained from Bangladesh. The RA was replaced with induction furnace slag from 0 to $100 \%$, at $25 \%$ intervals. They observed that the fresh characteristics satisfied the standard requirements. Likewise, as the compressive and split tensile strengths increased, total porosity and water absorption reduced up to $50 \%$ IFS content. From these, it was concluded that IFS could replace RA up to $50 \%$ in concrete. Alizadeh et al. [15] partially replaced IFS with coarse aggregates in normally-vibrated concrete. It was discovered that partially replacing IFS with the coarse aggregate improved the strength characteristics of the resulting concrete. Mahmood et al. [11] worked on the effects of partially replacing fine aggregate with IFS on the strength characteristics of rigid concrete pavement. The IFS was replaced with sand from 0 to $100 \%$ at $25 \%$ intervals. The compressive strength increased up to $25 \%$ IFS content, compared with the control. However, the flexural strength increased continuously over the control at all percentage replacement levels.

This study aims to develop self-compacting concrete using induction furnace slag as supplementary cementitious material between 0 and $50 \%$. The materials' physical and chemical properties were determined. The fresh properties and strength characteristics were also carried out to determine the optimum percentage replacement of IFS with Portland cement, and establish the feasibility and suitability of IFS as a sustainable material in the production of SCC. Also, the empirical correlations between the fresh and strength properties were analysed using MS Excel. Chemical and microstructural characterizations were conducted via XRF and SEM-EDS, respectively.

\section{Materials and methods}

\subsection{Materials}

Induction furnace slag was obtained at Nigeria Foundries Limited, Sango, Ota, Ogun State, Nigeria. It was crushed and milled using steel ball rolling mill at Highway and Transportation Laboratory of Covenant University, Ota, Ogun State, Nigeria. After that, it was sieved with $90 \mu \mathrm{m}$ sieve to obtain IFS, as shown in Fig. 1. The physical tests carried out on the IFS and Portland cement (PC), as shown in Table 1, were specific gravity, fineness, setting time, and standard consistency tests. Moreover, the fineness of IFS and PC was determined using the dry sieving method and BS sieve $90 \mu \mathrm{m}$. The oxide compositions of the IFS and PC were analyzed by X-ray fluorescence (XRF) analyzer. The results are shown in Table 2. The result of the specific gravity of the IFS was 2.95. The fineness of IFS was $8 \%$. The fineness of IFS was higher than that of the PC; indicating that fresh concrete's flowability would be retarded, while improving the concrete's strength. The utilization of IFS causes a reduction in the amount of free water present in the concrete mix because more water will be required. As presented in Table 2, $\mathrm{Al}_{2} \mathrm{O}_{3}+\mathrm{SiO}_{2}+\mathrm{Fe}_{2} \mathrm{O}_{3}$ for IFS was about $78.63 \%$. The main oxide content of IFS is silicon dioxide (silica, $\mathrm{SiO}_{2}$ ), contributing about $45 \%$ of the total oxide composition. It reacts with calcium hydroxide $\mathrm{Ca}(\mathrm{OH})_{2}$ from cement chemically, in the presence of moisture to form hydraulic cementitious compounds, referred to as calcium-silicate-hydrate (C-S-H) gel. Moreover, the maximum permissible loss of ignition (LOI) for blast furnace slag is $10 \%$. In the case of IFS, LOI was less than $10 \%$.

A 42.5R PC, the primary binder (Fig. 1), was obtained at a retail outlet in Ota, Ogun State, Nigeria. The result of specific gravity of cement was 3.06. The standard consistency showed that the water content was within the range of 25 to $35 \%$. The Portland cement's initial and final setting times were within the range of 30 to 600 minutes. The cement's fineness was $6 \%$, which was less than $10 \%$. The chemical composition of cement is as shown in Table 2. 

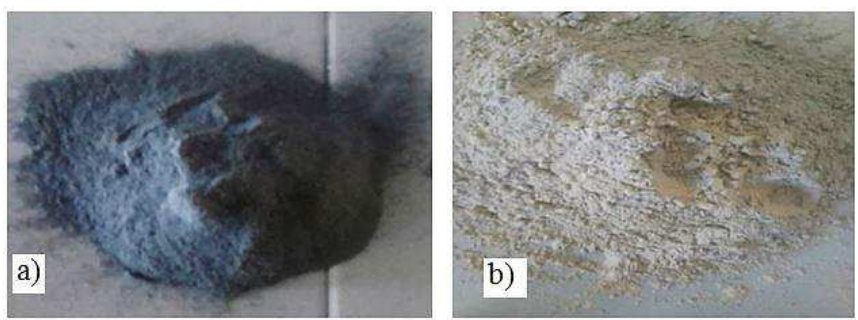

Fig. 1: Materials used: a) Induction furnace slag and b) 42.5R Portland cement.

Table 1: Physical properties of the binders used.

\begin{tabular}{|c|c|c|}
\hline Physical characteristics & PC & IFS \\
\hline Standard consistency [\%] & 30 & 33 \\
\hline Initial setting time [minutes] & 38 & 90 \\
\hline Final setting time [minutes] & 410 & 580 \\
\hline Fineness [\%] & 6 & 8 \\
\hline Specific gravity & 3.06 & 2.95 \\
\hline
\end{tabular}

Table 2: Chemical properties of the binders utilized.

\begin{tabular}{|c|c|c|}
\hline Oxide composition & PC [\%] & IFS [\%] \\
\hline $\mathrm{Al}_{2} \mathrm{O}_{3}$ & 4.98 & 11.10 \\
\hline $\mathrm{SiO}_{2}$ & 20.09 & 44.57 \\
\hline $\mathrm{Fe}_{2} \mathrm{O}_{3}$ & 1.80 & 22.97 \\
\hline $\mathrm{Na}_{2} \mathrm{O}$ & 0.21 & 0.44 \\
\hline $\mathrm{CaO}$ & 64.19 & 5.52 \\
\hline $\mathrm{K}_{2} \mathrm{O}$ & 0.53 & 0.33 \\
\hline $\mathrm{MnO}$ & - & 9.65 \\
\hline $\mathrm{MgO}$ & 1.92 & 1.62 \\
\hline $\mathrm{SO}_{3}$ & 1.80 & 0.33 \\
\hline $\mathrm{P}_{2} \mathrm{O}_{3}$ & - & 0.08 \\
\hline LOI & 0.08 & 9.97 \\
\hline
\end{tabular}

Locally available fine aggregate (river sand) and coarse aggregate (granite) were obtained from an aggregate depot, Ota, Nigeria. The nominal sizes of the river sand and granite, as obtained from the sieve analysis, were 4.75 and $12.5 \mathrm{~mm}$, respectively. Sieve analysis, Moisture content, specific gravity, bulk density, void content, and water absorption were conducted on the aggregates. The results are presented in Table 3. The specific gravity of river sand and granite were 2.64 and 2.66 , respectively. Also, the water absorption of river sand and granite used were 0.85 and $0.75 \%$, respectively. Moreover, the aggregates' void contents, as presented in Table 3 , conformed to the specified range of 28 to $52 \%$. The particle size distribution, as shown in Fig. 2, signified that the aggregates used were well-graded; this improves the flowing ability and segregation resistance of SCC. Also, the aggregates' moisture contents, as indicated in Table 3, satisfied the standard limit of $7 \%$ maximum. Ultimately, the physical properties of aggregates used satisfied the relevant standards and studies, hence, suitable for use in concrete's production.

Tap water, potable enough for drinking, was used as the mixing water for preparing and curing the concrete samples. A Polycarboxylate-based HRWR, commercially known as Complast SP 430 superplasticizer, was used to produce the required flowing ability of concrete.

Table 3: The physical properties of the aggregates used.

\begin{tabular}{|c|c|c|}
\hline Physical characteristics & River sand & Granite \\
\hline Natural moisture content [\%] & 0.80 & 0.09 \\
\hline Bulk density $\left[\mathrm{kg} / \mathrm{m}^{3}\right]$ & 1779 & 1671 \\
\hline Specific gravity & 2.64 & 2.66 \\
\hline Water absorption [\%] & 0.85 & 0.75 \\
\hline Void content [\%] & 32.60 & 37.20 \\
\hline
\end{tabular}



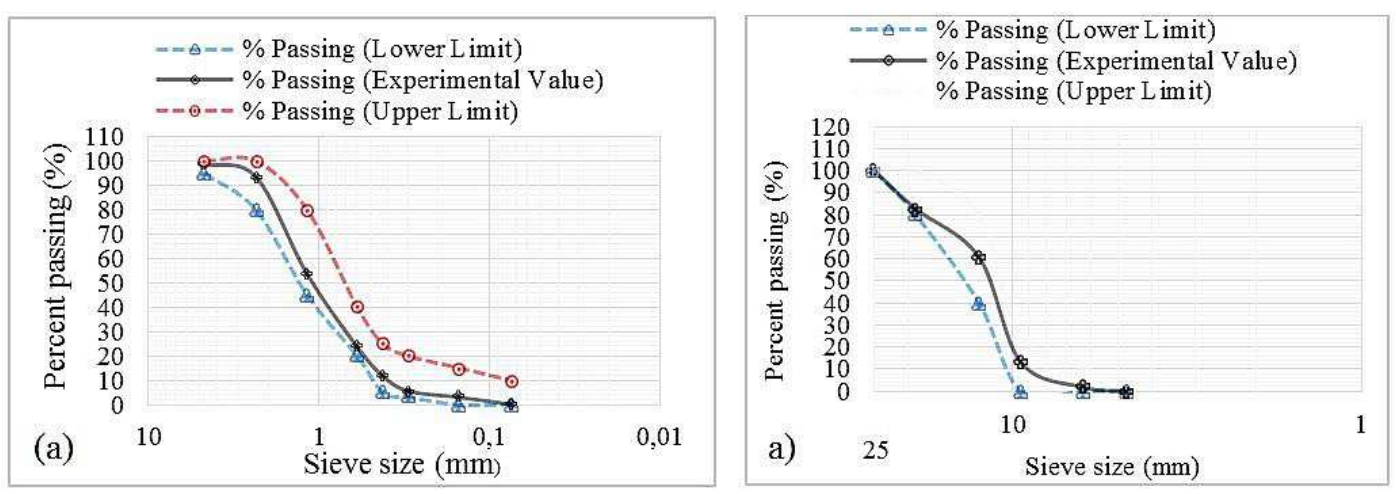

Fig. 2: Particle size distribution for: a) river sand and b) granite.

\subsection{Mixture proportioning of the SCC}

The percentage replacement of IFS with PC was $0,10,20,30,40$, and $50 \%$. In total, six different types of SCC mixtures were designed. The SCC was designed following the principle of Okamura and Ouchi [16]. The designation and description of the concrete mixtures are presented in Table 4. The concrete mix ratio was 1.00:1.02:0.95, while the water/binder ratio was 0.36 . The superplasticizer proportion was $2 \%$ weight of the binder content. The concrete mixes were designed based on the quantity of IFS. For instance, 'SCC0, 100' means a self-compacting concrete containing $0 \%$ IFS content, $100 \%$ cement content. The granite and river sand quantities were based on the saturated surface dry condition. However, the air-dry granite and river sand were utilized for preparing the SCC mixtures.

Table 4: Details of concrete mix proportions.

\begin{tabular}{|c|c|c|c|c|c|c|c|}
\hline S/N & Concrete type & $\begin{array}{c}\text { Cement } \\
{\left[\mathbf{k g} / \mathbf{m}^{3}\right]}\end{array}$ & $\begin{array}{c}\text { IFS } \\
{\left[\mathbf{k g} / \mathbf{m}^{3}\right]}\end{array}$ & $\begin{array}{c}\text { River sand } \\
{\left[\mathbf{k g} / \mathbf{m}^{3}\right]}\end{array}$ & $\begin{array}{c}\text { Granite } \\
{\left[\mathbf{k g} / \mathbf{m}^{3}\right]}\end{array}$ & $\begin{array}{c}\text { Water } \\
{\left[\mathbf{k g} / \mathbf{m}^{3}\right]}\end{array}$ & $\begin{array}{c}\text { Superplasticizer } \\
{\left[\mathbf{k g} / \mathbf{m}^{3}\right]}\end{array}$ \\
\hline 1 & SCC 0,100 & 733.0 & 0 & 747.66 & 696.35 & 263.88 & 14.66 \\
\hline 2 & SCC 10,90 & 659.7 & 73.3 & 747.66 & 696.35 & 263.88 & 14.66 \\
\hline 3 & SCC 20,80 & 586.4 & 146.6 & 747.66 & 696.35 & 263.88 & 14.66 \\
\hline 4 & SCC 30,70 & 513.1 & 219.9 & 747.66 & 696.35 & 263.88 & 14.66 \\
\hline 5 & SCC 40,60 & 439.8 & 293.2 & 747.66 & 696.35 & 263.88 & 14.66 \\
\hline 6 & SCC 50,50 & 366.5 & 366.5 & 747.66 & 696.35 & 263.88 & 14.66 \\
\hline
\end{tabular}

\subsection{Tests on the fresh SCC mixtures}

The fresh SCC mixtures were tested for slump flow using Abram's cone and $T_{500 \mathrm{~mm}}$ slump flow, L-box, and V-funnel at $T_{5 \text { minutes }}$.

\subsubsection{Slump flow test and $T_{500 \mathrm{~mm}}$ time}

Slump flow test was carried out using Abram's slump cone apparatus. This was conducted to measure the filling ability characteristics of the fresh SCC. The apparatus was filled with the fresh concrete in one layer, with no compaction form. The cone was vertically removed after about 5 seconds, to permit deformation of the concrete on a flat metal plate. A $T_{500 \mathrm{~mm}}$ slump flow time was taken when it took the fresh concrete to fill the $500 \mathrm{~mm}$ diameter circle drawn on the metal plate. The flow spread diameter was taken at four different points on the concrete, while the mean slump flow was taken as the slump flow value for the fresh SCC based on the according to EFNARC [17] procedure, as indicated Fig. 3.

\subsubsection{L-box test}

Passing ability characteristics of the fresh SCC was determined by carrying out the L-Box test, according to EFNARC [17], using an L-Box apparatus, as shown in Fig. 3. The apparatus was positioned on a flat surface ground, and its sliding gate closed. While the gate was still closed, the L-Box's vertical part was filled with the fresh concrete and allowed to settle for a minute. After that, the gate was opened, allowing the fresh concrete to pass through the gate to the L-Box's horizontal part. After the fresh concrete stopped passing, the concrete's heights in the box's horizontal and vertical 
parts were recorded as $H_{1}$ and $H_{2}$, respectively. The ratio $H_{2} / H_{1}$, known as the blocking ratio, was calculated.

\subsubsection{V-funnel at $T_{5 \text { minutes }}$ test}

Segregation resistance of the fresh SCC was determined by carrying out $V$-funnel at $T_{5 \text { minutes }}$ test using V-funnel apparatus, according to EFNARC [17], as indicated in Fig. 3. The apparatus was placed firmly on a hard flat surface ground with the inside wetted with clean water to avoid sticking of the concrete to the apparatus's walls. The fresh concrete was poured into the funnel, closing the trap door and placing the head pan under the apparatus to receive the concrete. After 5 minutes, the trap door was opened, and the concrete was discharged into the head pan. Simultaneously, a stopwatch was started, to measure the time it took for the fresh concrete to discharge into the head pan. This time was taken as the $T_{5 \text { minutes }}$ slump flow time.

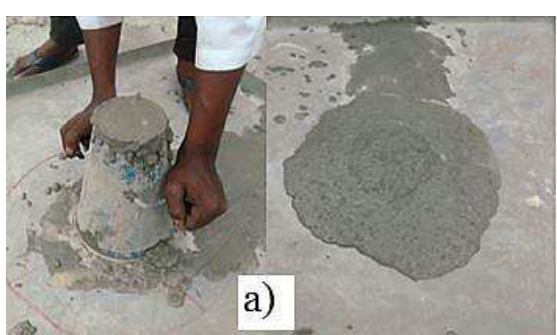

Fig. 3: Tests conducted: a) Slump flow and
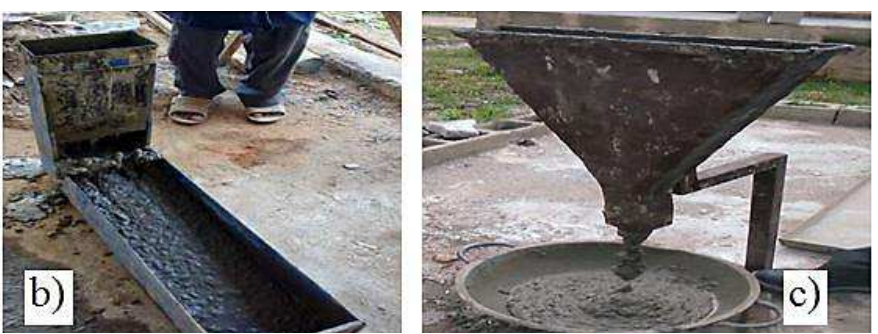
resistance test.

\subsection{Empirical correlations among the properties of fresh concrete}

The regression analysis among the fresh properties of SCC was performed using the MS Excel. The filling ability (slump flow) was correlated with the passing ability properties (L-Box). On the other hand, the filling ability ( $T_{50 \mathrm{~cm}}$ slump flow) was correlated with the segregation resistance (V-funnel at $\left.T_{5 \text { minutes }}\right)$.

\subsection{Preparation of specimens for strength tests}

Various procedures, including moulding, de-moulding, and curing, were carried out in preparing the samples needed for determining the strength characteristics of the SCC. Each mould was filled with fresh concrete in just one layer with no form of compaction. The moulds and their contents were then left undisturbed at the normal room temperature, well-labelled and covered with polythene bags. After a day, the hardened concrete samples were de-moulded and transported to the curing tank containing water until tested. Curing was done at $23 \pm 2{ }^{\circ} \mathrm{C}$ and $65 \pm 5 \%$ relative humidity $(R H)$.

\subsection{Tests on the mechanical properties of the hardened concretes}

The strength properties of the hardened specimens of various SCC were tested for compressive strength, split tensile strength, flexural strength and Schmidt/rebound number.

\subsubsection{Compression strength test}

Compressive strength of the hardened SCC was determined via compressive testing machine, Model YES-2000 with $2000 \mathrm{kN}$ maximum capacity, as shown in Fig. 4a), at 7, 28 and 56 days curing. The test was carried out on triplicate samples of $150 \times 150 \times 150 \mathrm{~mm}$ concrete cubes at each curing age. Fifty-four samples were crushed altogether, as indicated in Table 5.

Table 5: Experimental design for compressive strength's test.

\begin{tabular}{|c|c|c|}
\hline Factors & Levels & Description \\
\hline$\%$ IFS content & 6 & SCC 0,100, SCC 10,90, SCC 20,80, SCC 30,70, SCC 40,60, SCC 50,50 \\
\hline Curing age & 3 & 7,28 and 56 days \\
\hline Replicates & 3 & $150 \times 150 \times 150 \mathrm{~mm}$ concrete cubes \\
\hline Total number of cubes & 54 & $6 \times 3 \times 3$ \\
\hline
\end{tabular}




\subsubsection{Splitting tensile strength test}

Splitting tensile strength of the hardened SCC was determined using crushing testing machine, Model YES-2000 with 2000 kN maximum capacity, as shown in Fig. 4b, at 28 and 56 days curing. Thirty-six cylindrical concrete samples of $200 \mathrm{~mm}$ (length) $\times 100 \mathrm{~mm}$ (diameter) samples were tested altogether, as presented in Table 6 . Each sample was placed longitudinally in the crushing machine, and the load was applied perpendicularly till the sample failed. The maximum load at failure was noted and recorded.

Table 6: Experimental design for cylinders split tensile strength's test.

\begin{tabular}{|c|c|c|}
\hline Factors & Levels & Description \\
\hline$\%$ IFS content & 6 & SCC 0,100, SCC 10,90, SCC 20,80, SCC 30,70, SCC 40,60, SCC 50,50 \\
\hline Curing age & 2 & 28 and 56 days \\
\hline Replicates & 3 & $100 \times 200 \mathrm{~mm}$ concrete cylinders \\
\hline Total number of cylinders & 36 & $6 \times 2 \times 3$ \\
\hline
\end{tabular}

\subsubsection{Flexural strength test}

Flexural strength of the hardened SCC was determined via full automated transverse flexural testing machine, Model 2A8580, as shown in Fig. 4c, at 28 and 56 days curing. The test was carried out on triplicate samples of $100 \mathrm{~mm}$ (width) $\times 100 \mathrm{~mm}$ (depth) $\times 500 \mathrm{~mm}$ (length) concrete beams at each curing age. Thirty-six samples were tested altogether, as seen from the experimental design presented in Table 7. Each sample was positioned in the flexural testing machine on two roller supports, and the load was applied perpendicularly at the middle of the beam till the sample failed. The maximum load at failure was noted and recorded.

Table 7: Experimental design for concrete beams flexural strength's test.

\begin{tabular}{|c|c|c|}
\hline Factors & Levels & Description \\
\hline$\%$ IFS content & 6 & SCC 0,100, SCC 10,90, SCC 20,80, SCC 30,70, SCC 40,60, SCC 50,50 \\
\hline Curing age & 2 & 28 and 56 days \\
\hline Replicates & 3 & $100 \times 100 \times 500 \mathrm{~mm}$ concrete beams \\
\hline Total number of beams & 36 & $6 \times 2 \times 3$ \\
\hline
\end{tabular}

\subsubsection{Schmidt/rebound hammer test (non-destructive test method)}

Schmidt/rebound number of the hardened SCC was determined via Schmidt/rebound hammer (NDT) test, as shown in Fig. 4, at 28 and 56 days curing. The test was carried out on triplicate samples of $150 \times 150 \times 150 \mathrm{~mm}$ concrete cubes at each curing age. Thirty-six samples were tested, as presented in Table 8. Before testing, the samples were dried in the air for twenty-four hours and at ambient temperature to get a good result. With a predetermined amount of energy, a steel hammer was impacted on the concrete's surface. The distance that the hammer rebounded was measured as the Schmidt/rebound number, which was read from a graduated scale to the nearest whole number. Ten readings were taken, and the average rebound number was determined. Schmidt/rebound number's high value shows that the concrete is sufficiently hard and exhibits good quality.

Table 8: Experimental design for Schmidt/rebound hammer test.

\begin{tabular}{|c|c|c|}
\hline Factors & Levels & Description \\
\hline$\%$ IFS content & 6 & SCC 0,100, SCC 10,90, SCC 20,80, SCC 30,70, SCC 40,60, SCC 50,50 \\
\hline Curing age & 2 & 28 and 56 days \\
\hline Replicates & 3 & $150 \times 150 \times 150 \mathrm{~mm}$ concrete cubes \\
\hline Total number of cubes & 36 & $6 \times 2 \times 3$ \\
\hline
\end{tabular}




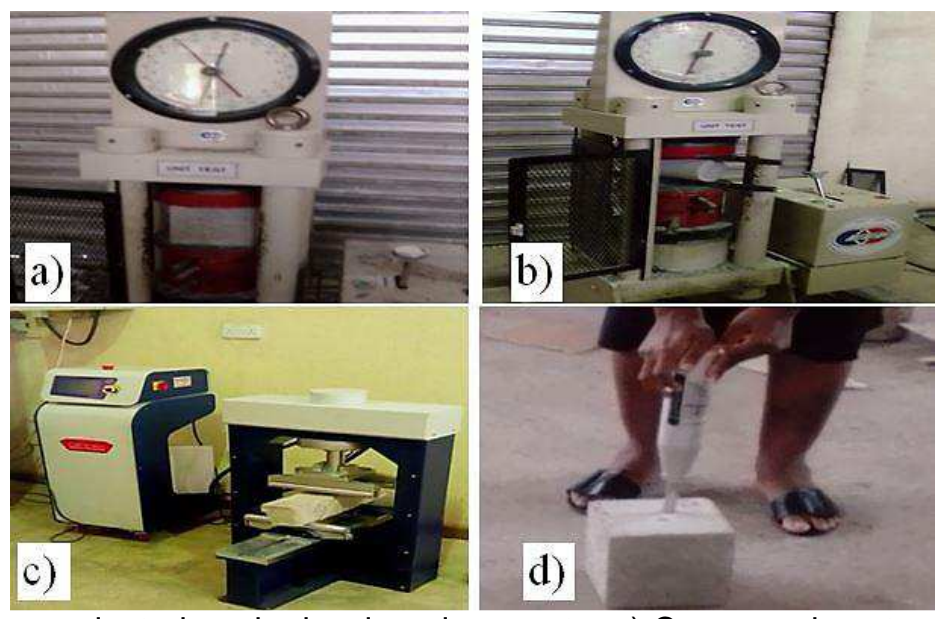

Fig. 4: Tests conducted on the hardened concrete: a) Compression strength; b) Split tensile strength; c) Flexural strength; d) Schmidt/rebound hammer.

\subsection{Empirical correlations among the strength characteristics}

The empirical correlations were statistically conducted using MS Excel to develop the regression equations. The compressive strength was correlated with the rebound number. Also, the compressive strength and split tensile strength, and the compressive strength and flexural strength were correlated.

\subsection{Microstructural analysis of SCC specimens}

The microstructural characterizations and elemental compositions of SCCs were analysed via SEM-EDS, Model JEOL 70006000, at 28 days of hydration. For the SEM analysis, the working distance was ranged between 9.5 to $12.4 \mathrm{~mm}$, while the magnification and accelerated voltage were constant at $8000 \mathrm{x}$ and $15 \mathrm{kV}$, respectively. The EDX analysis was conducted on a flat (general) scan. The samples were firmly held by an aluminium holder stub via a double sticky carbon tape, and carbon-coated.

\section{Results and discussion}

\subsection{Fresh properties of self-compacting concrete}

Table 9 presents the fresh SCC results for slump flow, $T_{500}$ slump flow time, L-box and V-funnel at $T_{5 \text { minutes }}$. For the slump flow result, the values were between 652 and $687 \mathrm{~mm}$. The values are within the stipulated range, 550 to $850 \mathrm{~mm}$, specified by relevant standard [18], indicating that the filling ability characteristic of the SCC was satisfied. However, as the percentage of IFS replacement increased, the slump flow value reduced. As presented in Table 9, the reduction in slump flow value was due to the increase in the volume of the paste content, drop in the quantities of granite and river sand, and increase in fineness of the IFS, hence requiring more water for easy flowability. Consequently, there was a decrease in the concrete deformation due to the lower inter-particle distance between the granite and rivers sand.

The $T_{500 \mathrm{~mm}}$ slump flow time of different SCC mixtures was between 2.59 and 3.97 seconds, as presented in Table 9, satisfying the 2-5 seconds of $T_{500 \mathrm{~mm}}$ slump flow recommended by EFNARC [17]. The $T_{500 \mathrm{~mm}}$ slump flow of concrete with higher IFS content was above the control mix due to the greater kinetic energy. As the percentage replacement of IFS increased at low water/binder ratio, the slump flow time increased, signifying an increment in the SCC plastic viscosity due to the increase in binder contents and its total surface area. The increase in the paste's quantity and the reduction in granite and river sand are also responsible for increasing slump flow value. The slump flow time values indicated that the filling ability characteristic was adequate.

The blocking ratio $h_{2} / h_{1}$ varied in the range of 0.81 to 0.95 , as shown in Table 9 . The blocking ratio $h_{2} / h_{1}$ for SCC often varies from 0.8 to 1.0 [17]. The minimum ratio $h_{2} / h_{1}$ was observed for SCC50, 50 , but the highest ratio $h_{2} / h_{1}$ was attained for SCC0, 100. The trend was similar, as observed for the SCC filling ability characteristics discussed above. The blocking ratio $\left(h_{2} / h_{1}\right)$ showed that the passing ability characteristic of the SCC was adequate. 
The $V$-funnel at $T_{5 \text { minutes }}$ varied in the range of 1.88 to 3.11 seconds, as shown in Table 9. The $V$-funnel at $T_{5 \text { minutes }}$ for SCC varies from 0 to 3 seconds [17]. The minimum value was observed for the SCC0, 100, but the highest value was attained for the SCC50, 50. The trend was similar as observed for the SCC slump flow discussed above. Ultimately, it can be inferred that the SCC V-funnel at $T_{5 \text { minutes }}$ exhibited a good segregation resistance.

Table 9: Fresh characteristics of the SCC.

\begin{tabular}{|c|c|c|c|c|}
\hline Concrete type & $\begin{array}{c}\text { Slump flow } \\
{[\mathbf{m m}]}\end{array}$ & $\begin{array}{c}\boldsymbol{T}_{\mathbf{5 0 0 m m}} \text { Slump flow } \\
{[\mathbf{s e c o n d s}]}\end{array}$ & $\begin{array}{c}\text { L-Box } \\
{\left[\boldsymbol{h}_{\mathbf{2}} / \boldsymbol{h}_{\mathbf{1}}\right]}\end{array}$ & $\begin{array}{c}\text { V-funnel at } \boldsymbol{T}_{\text {5minutes }} \\
\text { [seconds] }\end{array}$ \\
\hline SCC 0,100 & 687 & 2.59 & 0.95 & 1.88 \\
\hline SCC 10,90 & 685 & 2.80 & 0.92 & 2.56 \\
\hline SCC 20,80 & 680 & 3.72 & 0.90 & 3.00 \\
\hline SCC 30,70 & 670 & 3.84 & 0.88 & 3.05 \\
\hline SCC 40,60 & 657 & 3.93 & 0.83 & 3.08 \\
\hline SCC 50,50 & 652 & 3.97 & 0.81 & 3.11 \\
\hline
\end{tabular}

\subsection{Empirical correlations among the properties of fresh concrete}

The correlations between the filling ability (slump flow, SF) and passing ability properties (L-Box, LB), and filling ability ( $T_{500 \mathrm{~mm}}$ slump flow, TF) and segregation resistance (V-funnel at $T_{5 \text { minutes, }}$ VT) are indicated in Fig. 5. As shown in Fig. 5a, the slump flow (SF) exhibited a linear relationship and was strongly correlated with the L-Box. The coefficient of determination $R^{2}$ revealed that at least $97 \%$ of the data was accounted for in the regression analysis, hence strongly predicting the relationship at 95 $\%$ confidence interval $(\mathrm{Cl})$ and prediction interval $(\mathrm{PI})$. The strong correlation was obtained because the change in viscosity owing to various IFS contents followed a similar concrete trend. On the other hand, the regression analysis between the $T_{500} \mathrm{~mm}$ slump flow (TF) and the $\mathrm{V}$-funnel at $T_{5 \text { minutes }}(\mathrm{VT})$ were shown in Fig. 5b. A strong linear relationship also exists. The coefficient of determination $R^{2}$ revealed that about $88 \%$ of the data was accounted for in the analysis. Therefore, the relationship can strongly predict the selected variables at $95 \% \mathrm{Cl}$ and $\mathrm{PI}$.
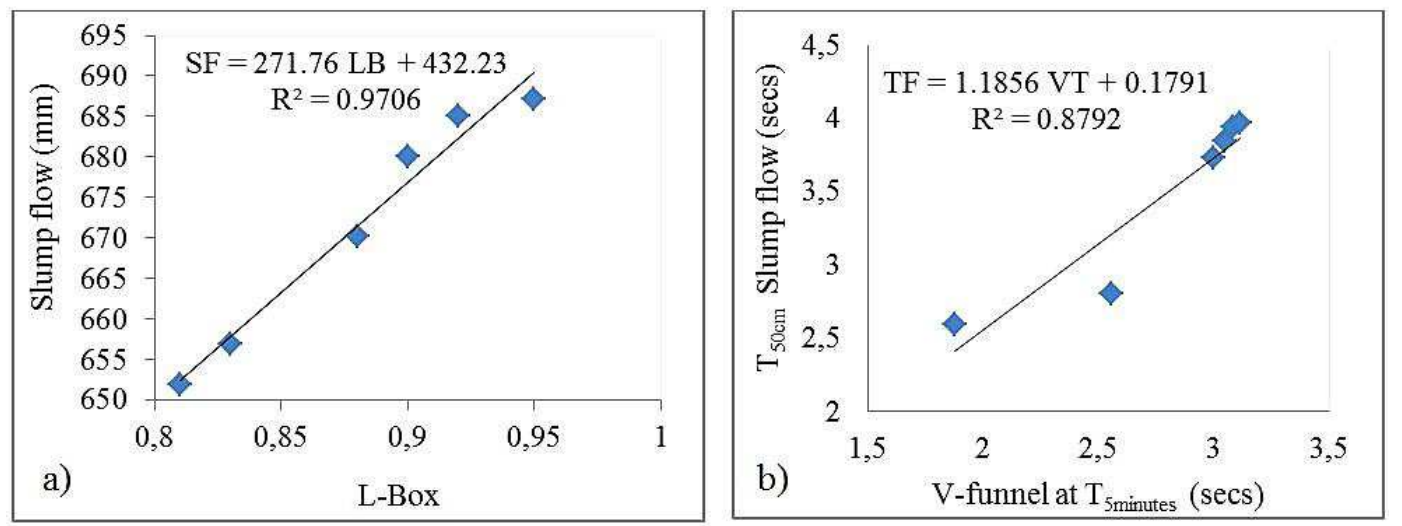

Fig. 5: Correlations between: a) Slump flow and L-Box; b) $T_{50 \mathrm{~cm}}$ Slump flow and V-funnel at $T_{5 \text { minutes. }}$.

\subsection{Mechanical properties of the hardened self-compacting concrete}

\subsubsection{Compressive strength}

The relation between the compressive strength and percentage replacement of induction furnace slag is presented in Fig. 6 . The average compressive strength, as shown in Fig. 6, indicated an increase in strength of the SCC from curing ages 7 to 56 days due to cement hydration. The curing ages 7 and 28 days exhibited the highest strength. SCC20, 80 had the highest compressive strength at 56 days curing. However, SCC50, 50 had the least compressive strength at 7 days curing. Notwithstanding, the performance criteria for early and later age compressive strength of concrete were satisfied for all the concrete types [19]. The increase in compressive strength may be attributed to the use of superplasticizer, leading to dense concretes with voids reduction. An increase in the IFS content with low water/binder ratio in SCC improved the granite and river sand packing structure, thereby enhancing the calcium silicate hydrate $(\mathrm{C}-\mathrm{S}-\mathrm{H})$. Moreover, IFS inclusion improved the 
compressive strength of the SCC both at early and later ages because of its micro-filling nature. Also, the chemical reaction of IFS with calcium hydroxide and water during mixing with PC results in the formation of calcium-silicate-hydrate (C-S-H), which is the main gel in the strengthening of concrete. Furthermore, the additional calcium silicate hydrate occupied the concrete voids, thereby decreasing the SCC void ratio (porosity), enriching the concrete microstructure in the interfacial transition zone resulting in higher compressive strengths. All concretes produced with IFS satisfied the compressive strength specification for an SCC [20]. Thus, higher compressive strengths were achieved for the SCC at 10 and $20 \%$ IFS substitution. There was a difficult mixing and handling with IFS content above $20 \%$ replacement due to low water/binder ratio. Therefore, $20 \%$ of IFS content is recommended as the optimum IFS percentage replacement with PC for the production SCC.

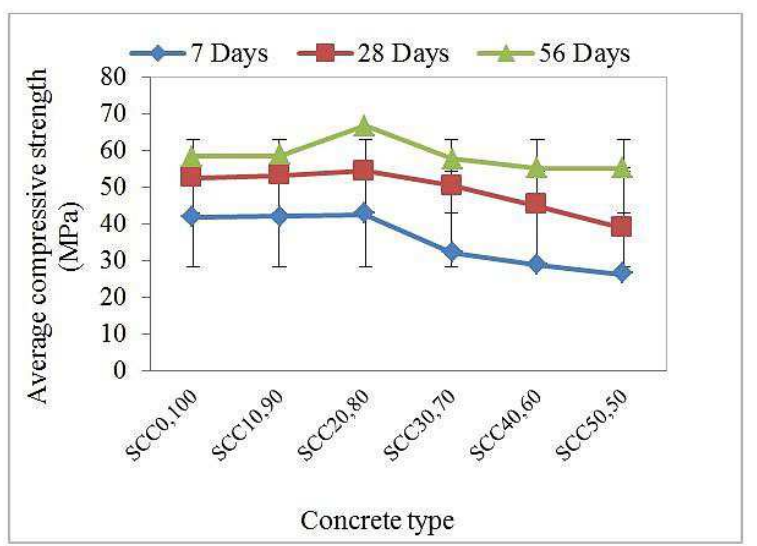

Fig. 6: Compressive strength of SCCs.

\subsubsection{Splitting tensile strength}

Fig. 7 shows the splitting tensile strength results for the 28 and 56 days curing. The result indicated that the splitting tensile strength increased as the curing age increased from 28 to 56 days. The IFS addition increased the splitting tensile strength up to $20 \%$ replacement level for all curing ages due to the micro-filling capability of the IFS, hence enhancing the strength. The highest value obtained at 28 days was $3.83 \mathrm{MPa}$, while the highest obtained at 56 days was $4.71 \mathrm{MPa}$.

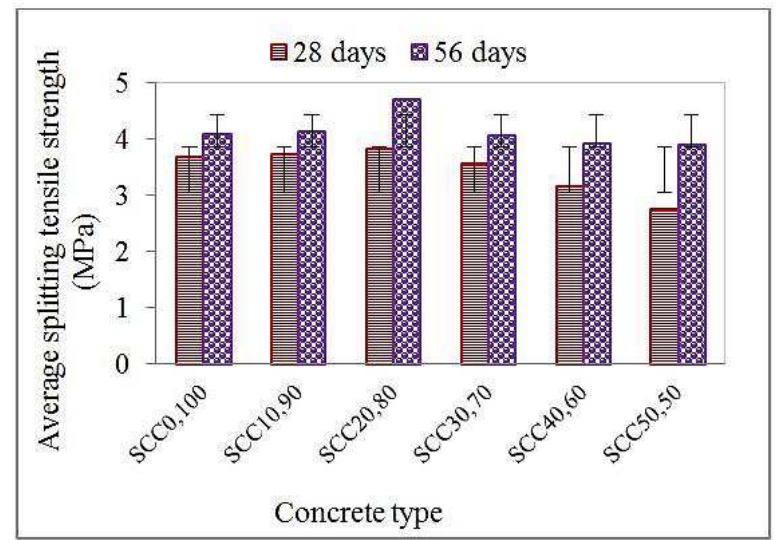

Fig. 7: Average splitting tensile strength of SCCs.

\subsubsection{Flexural strength}

The relation between the average flexural strength and percentage replacement of induction furnace slag is presented in Fig. 8. The results, as shown in Fig. 8, show that flexural strength increased as the curing age increased from 28 to 56 days. The IFS addition increased the flexural strength up to $20 \%$ replacement level for all curing ages owing to the void reducing characteristics of IFS, thus increasing the flexural strength. The highest value obtained at 28 days was $10.83 \mathrm{MPa}$, while the highest obtained at 56 days was $13.30 \mathrm{MPa}$. 


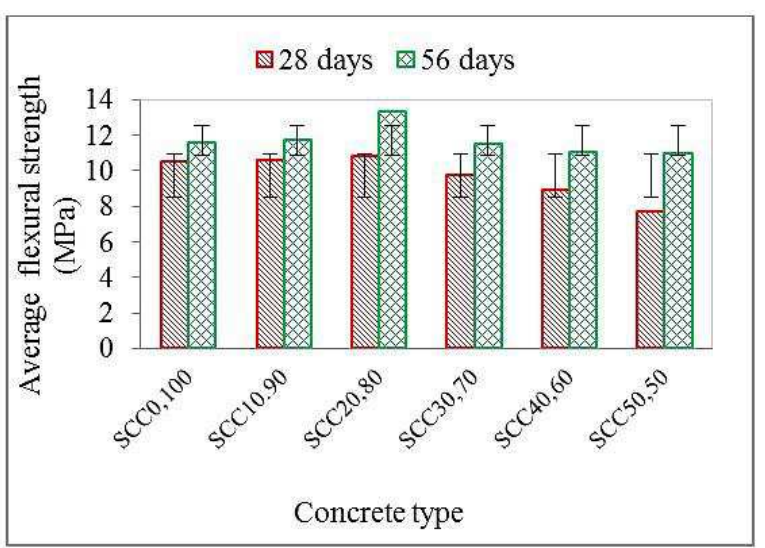

Fig. 8: Average flexural strength of SCCs.

\subsubsection{Rebound number/Schmidt number}

The average rebound number for the 28 and 56 days curing ages are presented in Fig. 9. The rebound number, as shown in Fig. 9, varied in the range of 30 to 51, indicating a perfect hard layer of the concretes. The reason is due to the fact that a rebound number higher than 30 generally shows an excellent concrete quality. The superior rebound numbers attained was mostly due to the improved pore structure of concretes resulting from the enhanced filling ability of IFS. Also, the rebound number of all concretes at 56 days was more significant than that of 28 days due to the reduction in voids, thus resulting in the continuous hydration of the cementitious materials.

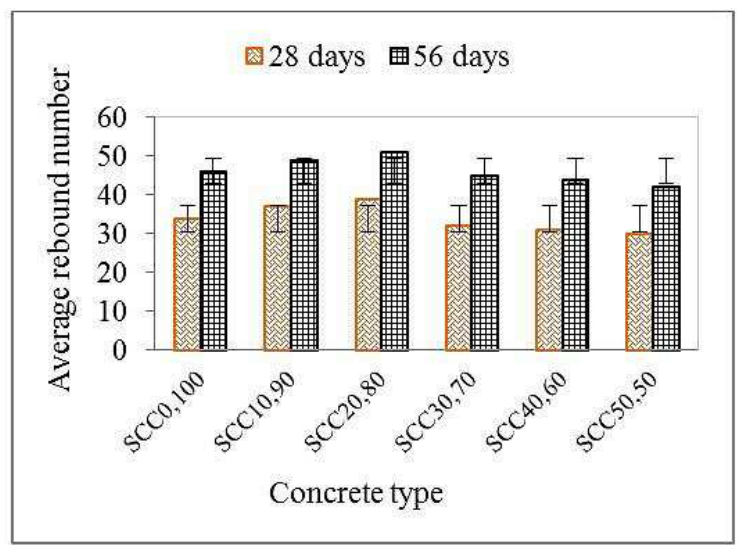

Fig. 9: Average rebound number of SCCs.

\subsection{Empirical correlations among the strength properties}

The correlations, between the compressive strength and rebound number, compressive strength and split tensile strength, and the compressive strength and flexural strength, were determined and presented in Fig. 10.

As shown in Fig. 10a, a linear relationship was observed between the compressive strength and rebound number for all the concrete types, as can be seen from Fig. 11. The regression equation was developed for the compressive strength (CS) values ranging from 38.67 to $66.79 \mathrm{MPa}$ and the rebound number (RN) ranging from 30 to 51 . The coefficients of determination $R^{2}$ for the best-fit curve at 28 and 56 days curing were 81 and $91 \%$, respectively. This signifies that the model can strongly predict the relationship at $95 \% \mathrm{Cl}$ and PI. Therefore, the relationship between the compressive strength and rebound number is independent of the concrete age because both the compressive strength and rebound number increase with concrete's curing age [21].

A linear relationship was also observed between the compressive strength and split tensile strength of all the concrete types, as indicated in Fig. 10b. The model was statistically developed using the compressive strength (CS) and splitting tensile strength (ST), ranging from 38.67 to $66.79 \mathrm{MPa}$ and 2.76 to $4.71 \mathrm{MPa}$, respectively. The coefficients of determination $R^{2}$ for the best-fit curve were 0.9985 and 0.9992 at 28 and 56 days curing, indicating a strong correlation at about $95 \% \mathrm{Cl}$ and $\mathrm{PI}$. 
Fig. 10c shows a strong linear relationship between the compressive strength and flexural strength for all the concrete types. The regression equation was developed using the compressive strengths ranging from 38.67 to $66.79 \mathrm{MPa}$ and the flexural strength varying from 7.71 to $13.30 \mathrm{MPa}$. The coefficients of determination $R^{2}$ for the best-fit curve were 99.6 and $99.8 \%$ at 28 and 56 days curing, respectively. Therefore, the model can be used to predict the relationship between the compressive strength and flexural strength of SCC at about $95 \% \mathrm{Cl}$ and PI.

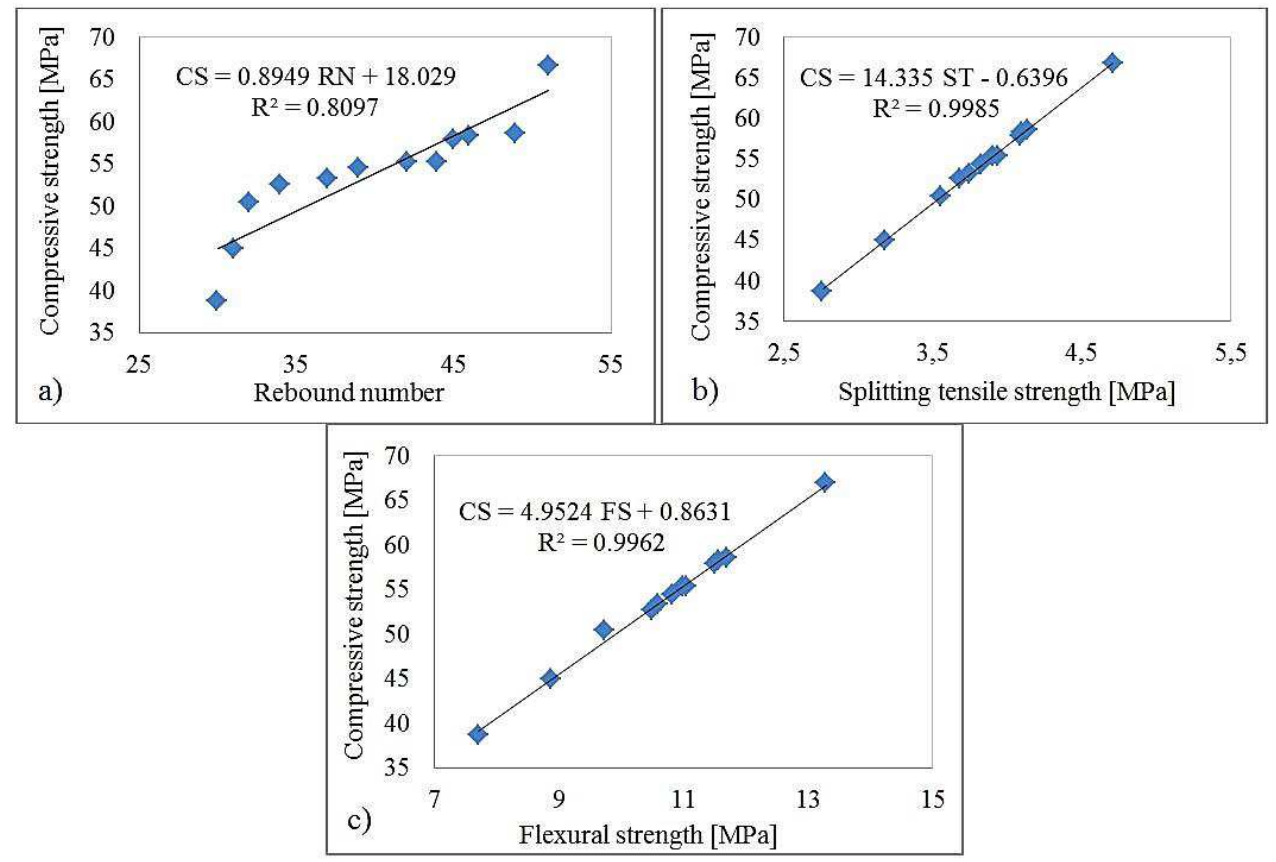

Fig. 10: Correlation between a) compressive strength and rebound number, b) compressive and splitting tensile strengths, and c) compressive and flexural strengths.

\subsection{Microstructural characteristics of SCCs}

The results of microstructures and elemental compositions of the SCC samples at 28 days curing using SEM-EDS are presented in Fig. 11. As indicated in Fig. 11a, the morphology revealed an irregular shape structure with better interface condition, indicating an adequate compact and uniform matrix. In the same vein, the inclusion of IFS, as shown in Fig. $11 \mathrm{c}, \mathrm{e}, \mathrm{g}, \mathrm{i}$, and $\mathrm{k}$ revealed the amorphous structures with better interface conditions, signifying an adequate compact and uniform matrix between the constituent particles and the cementitious matrix. However, the SEM micrographs, as shown in Fig. 11c and e revealed the refined patterns, and voids were rarely noticed compared with SEM micrographs indicated in Fig. $11 \mathrm{~g}$, i and $\mathrm{k}$. Thus, these could be responsible for higher mechanical strengths with increasing IFS content in the mix up to $20 \%$.

The results of the energy dispersive $x$-ray spectrometry (EDS) analysis on the concrete samples, as shown in Fig. $11 \mathrm{~b}, \mathrm{~d}, \mathrm{f}, \mathrm{h}, \mathrm{j}$, and I revealed the dominant chemical elements present in each sample. The EDS analysis revealed the presence of calcium $\mathrm{Ca}$, silicon $\mathrm{Si}$, oxygen $\mathrm{O}$, aluminium $\mathrm{Al}$ and iron $\mathrm{Fe}$ as significant elements, indicating the presence of calcium-silicate-hydrate (C-S-H) in all samples. The aggregate fractions contributed to the presence of silicon in the mixes. The total atomic mass of calcium, silicon, and oxygen, which are the major elements of the calcium-silicate-hydrate of SCC 0, 100, SCC 10, 90, SCC 20, 80, SCC 30,70, SCC 40, 60, and SCC 50, 50, were 68.0, 65.9, $68.6,70.8,75.9$, and $85.9 \%$, respectively. These results signified that the IFS addition yielded greater hydration of the cementitious pastes over the control. The calcium-silicate-hydrate contents were higher than the control, thereby improving the strength performance of SCCs and providing denser concretes with minimum voids. Moreover, the intensity of calcium counts in the mixes incorporating IFS was higher than the control, SCC0, 100. There was about 22, 47, 59, 79, and $82 \%$ increase in calcium counts in SCC10, 90, SCC20, 80, SCC30,70, SCC40, 60, and SCC50, 50 compared with the control, SCC0, 100. The calcium present in IFS is tied up as calcium silicate, calcium aluminate, and calcium aluminosilicate, hence reason for higher calcium counts [22]. During the pozzolanic reaction, samples with IFS are virtually impermeable to oxygen in normal environment, hence reduced the silica and increased the ferrite and resulted mostly in calcium aluminoilicate hydrate [11]. 

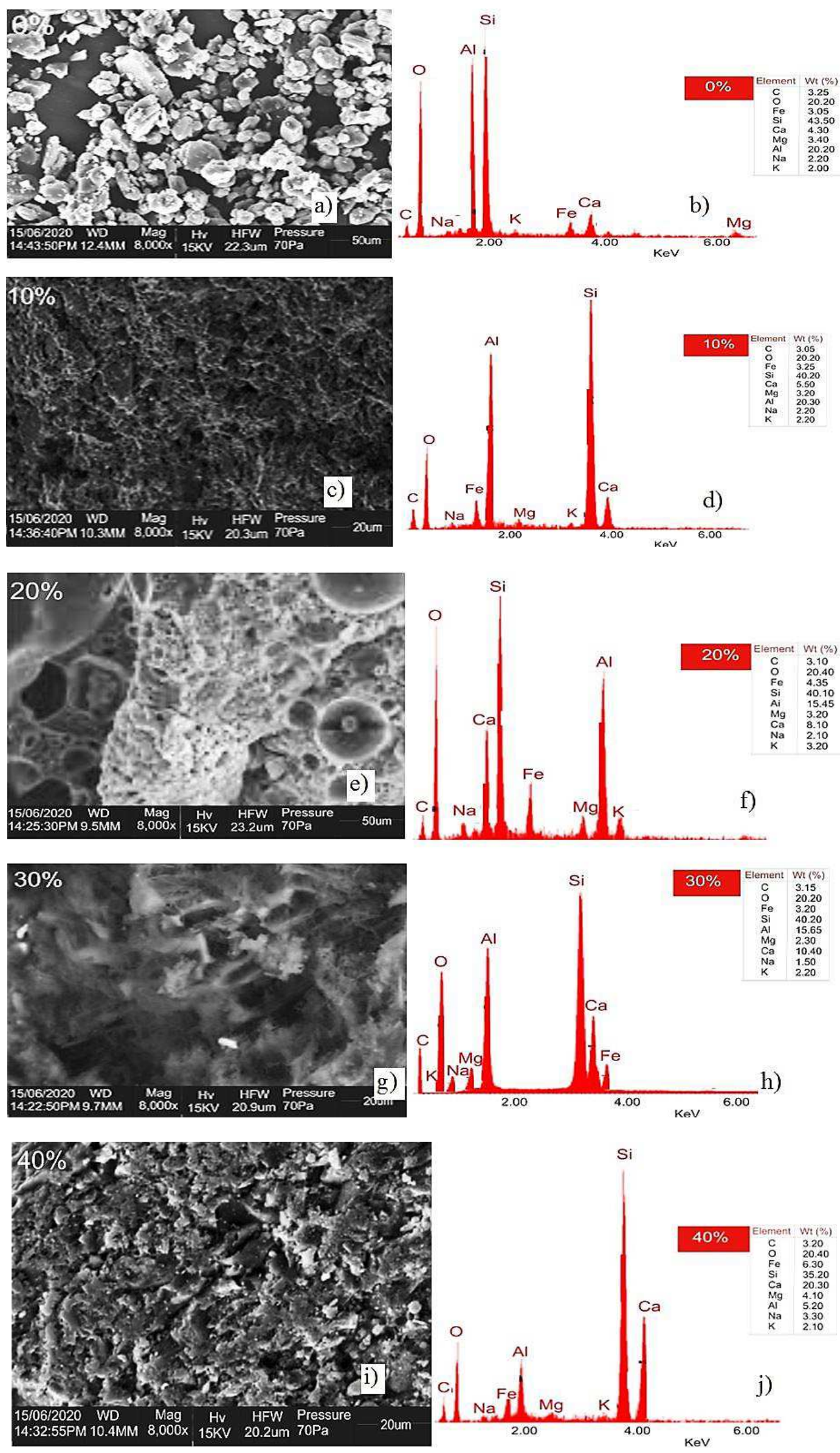

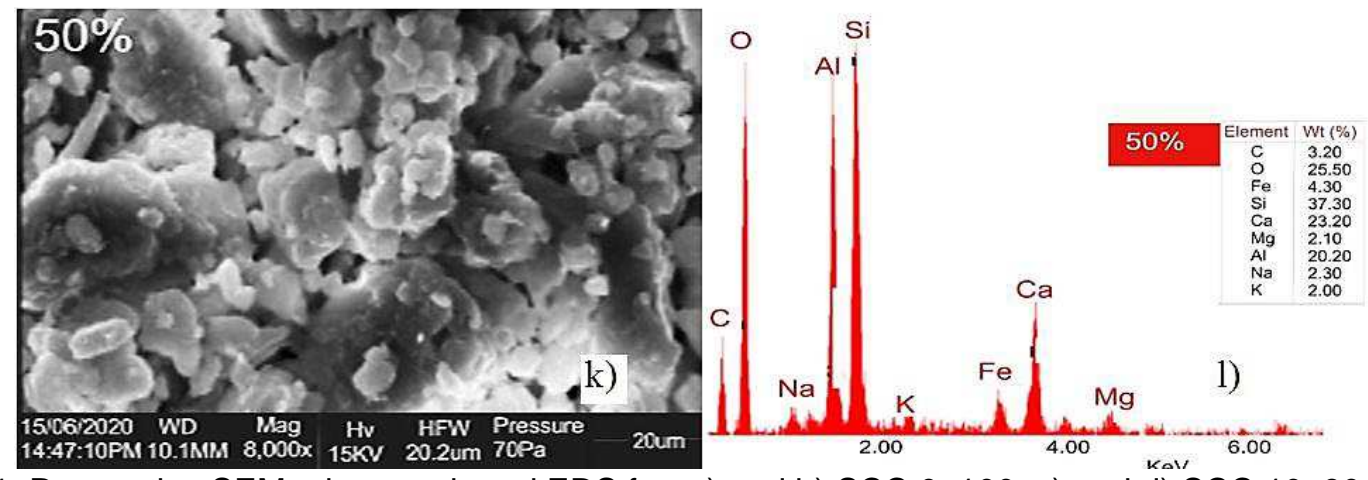

Fig. 11: Respective SEM micrograph and EDS for: a) and b) SCC 0, 100; c) and d) SCC 10, 90; e) and f) SCC 20, 80; g) and h) SCC 30, 70; i) and j) SCC 40, 60; k) and I) SCC 50, 50.

\section{Conclusions}

This study investigated the effects of induction furnace slag on the fresh and mechanical properties of cement-based self-compacting concrete (SCC). Induction furnace slag (IFS) was harnessed and used as supplementary cementitious material. The SEM-EDS of SCCs were analysed. Thus, based on the experimental and statistical results, the following conclusions are arrived at:

- There was about $0.3-5 \%$ decrease in slump flow of SCCs as the percentage substitution of IFS in the mix increased from $10-50 \%$ compared with the control mix (SCC0, 100).

- $T_{500 \mathrm{~mm}}$ slump flow increased from 8 - $35 \%$ with 10 - $50 \%$ increasing IFS content in the mix compared with the control mix.

- At 10 - 50 \% IFS replacement level, there was about 3 - $15 \%$ decrease in L-Box compared with the control mix.

- Strength properties of the SCCs increased with increasing IFS content. However, the targeted strength was satisfied at $20 \%$ IFS maximum replacement level.

- There was about $0.5-13 \%, 1-13 \%$, and $1-13 \%$ increase in compressive strength, splitting tensile strength, and flexural strength, respectively as the curing ages increased from 7 - 56 days at $10-20 \%$ IFS replacement level in the mixes compared with the control mix.

- The strong correlations exist among the fresh characteristics and the strength properties of SCCs with about $81-100 \% R^{2}$ at $95 \% \mathrm{Cl}$ and $\mathrm{PI}$.

- The microstructural examinations revealed the amorphous and homogeneous matrices, and better cohesiveness and interface with increasing IFS content in the mix. Also, there was an increase in calcium counts with increasing IFS content in the mix.

The production of self-compacting concrete incorporating IFS as industrial waste is attainable. This research benefits future study and the technological advancement of SCC by focussing on three prospective solutions. First, IFS can be recycled, hence reducing its indiscriminate disposal, which portends serious environmental challenges. Second, IFS can be used as an alternative SCM, which is more eco-friendly than the PC. Third, the developed models can be applied in the strength prediction of SCC incorporating IFS as industrial by-product.

\section{Acknowledgement}

The authors would like to appreciate Covenant University Centre for Research, Innovation and Discovery for the financial support.

\section{References}

[1] MOHANKUMAR, N. B.: High Quality Concrete Comprising of Several Mix of ACM's. Civil and Environmental Engineering, Vol. 16, Iss. 1, 2020, pp. 138-147.

[2] OYEBISI, S. - EDE, A. - OLUTOGE, F. - OLUKANNI, D.: Assessment of Activity Moduli and Acidic Resistance of Slag-based Geopolymer Concrete Incorporating Pozzolan. Case Studies. Construction. Materials, Vol. 13, e00393, 2020, pp. 1-20.

[3] OYEBISI, S. - EDE, A. - OLUTOGE, F. - OMOLE, D.: Geopolymer Concrete Incorporating Agroindustrial Wastes: Effects on Mechanical Properties, Microstructural Behaviour and Mineralogical Phases. Construction and Building. Materials, Vol. 256, 119390, 2020, pp. 1-22.

[4] OFUYATAN, O. - EDEKI, S.: Dataset on Predictive Compressive Strength Model for SelfCompacting Concrete. Data in Brief, Vol. 17, 2018, pp. 801-806. 
[5] MEHTA, P. K.: High-volume Fly Ash Concrete for Sustainable Development. Concrete International Journal, Vol. 3, 2016, pp. 10-19.

[6] FALMATA, A. M. - SULAIMAN, A. - MOHAMED, R. N. - SHETTIMA, A. N.: Mechanical Properties of Self-Compacting High-Performance Concrete with Fly Ash and Silica Fume. SN Application of Science, Vol. 33, 2019, pp. 1-10.

[7] ASKARI, A. - SOHRABI, M. R. - RAHMANI, Y.: An Investigation into Mechanical Properties of SelfCompacting Concrete Incorporating Fly Ash and Silica Fume at Different Ages of Curing. Advanced. Materials. Journal, Vol. 3, 2018, pp. 261-263.

[8] AHMED, S. D. - RIDHA, A. L.: The Influence of the Size of Lightweight Aggregate on the Mechanical Properties of SCC with and without Steel Fibre. International Journal of Structural and Civil Engineering Research, Vol. 3, Iss. 1, 2017, pp. 55-68.

[9] SNEHAL, A. - PATEL, D. - PATEL, N.: Effect of High Volume Fly Ash on Rheological Properties of SCC. International Journal of Emerging Technological Advancement in Engineering, Vol. 3, Iss. 7 , 2016, pp. 559-565.

[10] ANNIE, J. - LAKSHMANAN, P. N. - MANOHARAN, P. D.: Investigation on the Static Behaviour of Self-Compacting Concrete under Reamed Piles. Journal of Materials in Civil Engineering, Vol. 18, Iss. 3, 2016, pp. 408-411.

[11] MAHMOOD, A. N. - MOHAMMED, T. U. - HASNAT, A. - AWAL, M. A.: Evaluation of the Use of Air-Cooled Induction Furnace Slag as a Replacement for Natural Aggregate in Concrete Pavements. Journal of Materials in Civil Engineering, Vol. 27, 2017, pp. 1-10.

[12] NETINGER, I. - RUKAVINA, M. J. - BJEGOVIC, D. - MLADENOVIC, A.: Concrete Containing Induction Furnace Slag Aggregate: Performance after High-Temperature Exposure, 2016.

[13] JOHN, A. - JOHN, E.: Study on the Partial Replacement of Fine Aggregate using Induction Furnace Slag. American Journal of Engineering Research, Vol. 4, 2019, pp. 1-5.

[14] SYED, I. A. - SHAFIQUR, M. R.: Mechanical and Durability Properties of Induction-Furnace-SlagIncorporated Recycled Aggregate Concrete. Advance in Civil Engineering Journal, Vol. 6, 2018, pp. $1-11$

[15] ALIZADEH, R. - CHINI, M. - GHODS, P. - HOSEINI, M. - MONTAZER, I. - SHERKACHI, M.: Utilization of Electric Arc Furnace Slag as Aggregate in Concrete, 6th ACl International Conference on Recent Advances in Concrete Technology, Bucharest, Romania, 2018.

[16] OKAMURA, H. - OUCHI, M.: Self-Compacting Concrete. Journal of Advanced Concrete Technology. Vol. 1, 2003, pp. 1-12.

[17] EUROPEAN FEDERATION OF NATIONAL ASSOCIATIONS REPRESENTING PRODUCERS AND APPLICATORS OF SPECIALIST BUILDING PRODUCTS FOR CONCRETE: Specifications and Guidelines for Self-Consolidating Concrete. European Federation of Suppliers of Specialist Construction Chemicals (EFNARC), Surrey, UK, 2002, pp. 1-32.

[18] SELF-COMPACTING CONCRETE. EUROPEAN PROJECT GROUP: The European Guidelines for Self-Compacting Concrete: Specification, Production and Use, Self-Compacting Concrete. European Project Group, the European Federation of Concrete Admixtures Associations, West Midlands, UK, 2005, pp. 1-63.

[19] HEARN, N.: Pore Structure and Permeability. Significance of Tests and Properties of Concrete and Concrete-Making Materials, ASTM STP 169C, American Society for Testing and Materials, Philadelphia, USA, 2016, pp. 240-262.

[20] YU, Q. - SAWAYAMA, K. - SUGITA, S. - SHOYA, M. - ISOJIMA, Y.: The Reaction between Rice Husk Ash and $\mathrm{Ca}(\mathrm{OH})_{2}$ Solution and the Nature of its Product. Cement and Concrete Research, Vol. 29, 2009, pp. 37-43.

[21] KAPLAN, M. F.: Compressive Strength and NDT Relationships for Concrete in Columns. Proceedings of American Concrete. Institute, VOL. 54, 2018, pp. 675-688.

[22] OYEBISI, S. - EDE, A. - OLUTOGE, F. - OGBIYE, S.: Evaluation of Reactivity Indexes and Durability Properties of Slag-Based Geopolymer Concrete Incorporating Corn Cob Ash. Construction and Building. Materials, Vol. 258, 119604, 2020, pp. 1-15. 